\title{
Distributed Hydrological Model for Assessing Flood Hazards in Laos
}

\author{
Sengphrachanh Phrakonkham¹, So Kazama1, Daisuke Komori', Soliya Sopha² \\ ${ }^{1}$ Department of Civil Engineering, Tohoku University, Sendai, Japan \\ ${ }^{2}$ Deaprtment of Frontier science for Advance Environment, Tohoku University, Sendai, Japan \\ Email: nh.t7@dc.tohoku.ac.jp
}

How to cite this paper: Phrakonkham, S., Kazama, S., Komori, D. and Sopha, S. (2019) Distributed Hydrological Model for Assessing Flood Hazards in Laos. Journal of Water Resource and Protection, 11, 937-958.

https://doi.org/10.4236/jwarp.2019.118056

Received: June 26, 2019

Accepted: August 10, 2019

Published: August 13, 2019

Copyright $\odot 2019$ by author(s) and Scientific Research Publishing Inc. This work is licensed under the Creative Commons Attribution International License (CC BY 4.0).

http://creativecommons.org/licenses/by/4.0/

\begin{abstract}
Many natural disasters have recently occurred in Laos. Among them, flooding has been the greatest problem. Land use change (deforestation and urbanization) and climate change have played significant roles, and it is important to understand the impacts of these changes on flooding. We have developed an integrated hazard map based on a combination of four hazard maps of flooding, land use change and climate change to assess hazard areas at the national scale. The hazard map was developed using the analytical hierarchy process (AHP) and a hazard index. Finally, we divided the map into four hazard area categories, which include low, medium, intermediate and high. Based on this analysis, the integrated hazard map of Laos indicates that low hazard areas cover $87.44 \%$ of the total area, medium hazard areas cover $8.12 \%$, and intermediate and high hazard areas respectively cover $2.42 \%$ and $2 \%$ of the land area. We compared the results with historical events to confirm that the proposed methodology is valid.
\end{abstract}

\section{Keywords}

Flood, Land Use Change, Climate Change

\section{Introduction}

Lao People's Democratic Republic, or Laos, is a country in Southeast Asia. The country is landlocked with no direct access to the sea, and it shares common borders with China, Vietnam, Cambodia, Myanmar, and Thailand. In recent decades, Laos has encountered many floods of different magnitude and duration. Over three consecutive years from 1994 to 1996, the floods were large and disastrous. More recently, Laos has rapidly developed both socially and economically, but most Laotian incomes originate from natural resources and agri- 
cultural products. However, water systems in rural areas are not well distributed. Only areas located along rivers or where irrigation has been developed are suitable for agriculture; hence, most of the rural population tends to settle and live downstream from dams [1]. However, floods are one of the major problems causing both social and economic damage to the country. Moreover, damage caused by floods could significantly increase in the future due to socioeconomic growth and climate change [2]. A flood hazard map would help reduce these damages. A map is a tool for assisting decision makers to prioritize plans for hazard mitigation, develop response efforts, and identify areas prone to flooding. Hence, to determine suitable areas for development, it is important to identify locations and their flood susceptibility range.

Over the last few decades, floods have become one of the main problems causing damage to human and animal lives, infrastructure, and agricultural and economic areas [3]. Furthermore, in the near future, socioeconomic development, climate change and the decrease in forest density could significantly increase the impact of floods [2] [4]. However, the impact of floods can be reduced by developing a flood risk map. Generally, flood risk maps are generated based on a combination of factors related to hazards (physical) and vulnerability (socioeconomic). Current global flood models can be unsuccessful in precisely predicting the dynamics of climate change and socioeconomic development [4]. Nevertheless, knowledge of flood hazards plays an important role in the strategy for minimizing flood risks such as reducing damage in agricultural areas and losses of animal and human lives. In addition, decision-makers can create future development plans. Flood hazards can be quantified by considering the occurrence probability of potentially damaging events. The occurrence probability can serve as an indicator for verifying the sensitivity of such areas. Many researchers have developed reliable flood hazard maps as a basis for generating flood risk maps to support flood mitigation plans [5] [6]. However, many countries in the Southeast Asia area still lack flood hazard maps.

To date, there has only been limited assessment, analysis or projections regarding potential climate change impacts on the physical and social environment in Lao PDR. The Intergovernmental Panel on Climate Change (IPCC) has found that floods will tend to occur more frequently in Southeast Asia in the future [7]. The occurrence of climate change can lead to increases in heavy rainfall and flooding [8], and floods are one of the most dangerous hazards to the economy and human lives, especially for developing countries like Laos.

Hazards can be single or combined in their origins and effects on an area. In recent decades, many researchers have paid attention to the used of multi-hazard assessment, which focuses on all scales. For example, Marzocchiet [9] used the multi-hazard assessment at the medium scale in their studies. Large scale studies involving the multi-hazard assessment include those of [10] [11]. In addition, several models have been developed for estimating the risk of multi-hazards, but most of these models are very data intensive. 
Recently, many studies have used geographic information systems (GIS), which are a powerful tool for managing large volumes of spatial data, integrating data from different sources and performing analyses [12] [13]. Nevertheless, for decision-making purposes, GIS applications are inefficient for use in multiple criteria analyses. To use GIS for multi-criteria decision-making, it is necessary to combine GIS with multi-criteria decision analysis (MCDA). Several studies have shown that coupling GIS with MCDA can be used to generate a flood hazard map. Among MCDA methods, the analytic hierarchy process is the most popular because it is a user-friendly, convenient method that provides accurate results and is suitable for other hazard studies [13] [14]. Until recently, flood hazard mapping using AHP and GIS has been applied using GIS-based map information such as slope, flow accumulation, elevation, land use, and rainfall intensity [15].

Regarding the region, there is a difference between the impact of land use change and climate change to flood [16] [17]. Characteristic of hazards in each region can lead to the transformation of future land use to lower the impact of the flood. Therefore, it is important to understand the characteristic of hazards in each region. Understanding the factor that driven regional sensitivity is essential for future mitigation and adaptation strategies for instance based on Laos national report [18]. The magnitude of hazard is increasing in the northern and southern part of Laos because of the climate change.

The main objective of this study is to propose a reliable and capable of AHP method to integrate hazard maps to gather and the integrated hazard map can be used to identify sensitive areas over the region with limited available data. The modeling method combines different hazard maps including flood, land use change, and climate change. AHP is used as a tool to weigh the priority of the maps. The proposed methodology provides an integrated hazard map that can be used as a guide map, which provides important information for developing countermeasures for floods, as well as other natural hazards. The map index is shown on a scale from zero, which means low hazard to one, which means high hazard probability. This is also the first time a hazard map for the entire country of Laos has been developed. Another advantage of this proposed study is that the AHP weights used to develop unified hazard maps are based on the decision maker's design criteria and the priorities. It is helpful to identify hazard areas and focus on potential impact areas.

\section{Study Area and Dataset}

Located in the center of the Indochinese Peninsula, Laos is situated between longitudes $100^{\circ}$ and $108^{\circ} \mathrm{E}$ and latitudes $14^{\circ}$ and $23^{\circ} \mathrm{N}$. The country has a total area of $236,800 \mathrm{~km}^{2}$, with the Mekong River flowing through approximately $1900 \mathrm{~km}$ of its territory from north to south and with over $800 \mathrm{~km}$ comprising a natural border with Thailand.

Land use in Laos is classified as forests (65.2\%), vegetation or agricultural 
areas (33.8\%), and water bodies and bare land (1\%). Almost all agricultural areas are paddies. Land use type is one of the factors used to determine water infiltration. Soil data are based on the Harmonized World Soil Database, which is a 30 arc-second raster database with over 16,000 different soil mapping units; it combines existing regional and national soil information updates worldwide with the information contained within the 1:5,000,000 scale FAO-UNESCO Soil Map of the World. The original soil type data based on the global soil unit (SU) was converted to the soil texture class. The soil type data plays an important role in the infiltration factor of the hydrological distribution. Based on the government the country can separately into 3 regional areas namely, northern, central and southern region (Figure 1).

To simulate hydrological distributed models, a hydrological and meteorological dataset from the Mekong River Commission is used. The daily meteorological data at 40 stations for the period of 1970 to 2000 is used for the rainfall-runoff simulation and for calibration and validation of the distributed hydrological model (Figure 1). The parameters include precipitation, soil types, and elevation. In addition to the rainfall data, daily maximum data were selected to analyze the rainfall intensity for 50 and 100-year return periods (Figure 2). The rainfall intensity for many return periods was calculated using the Log-Pearson Type III.

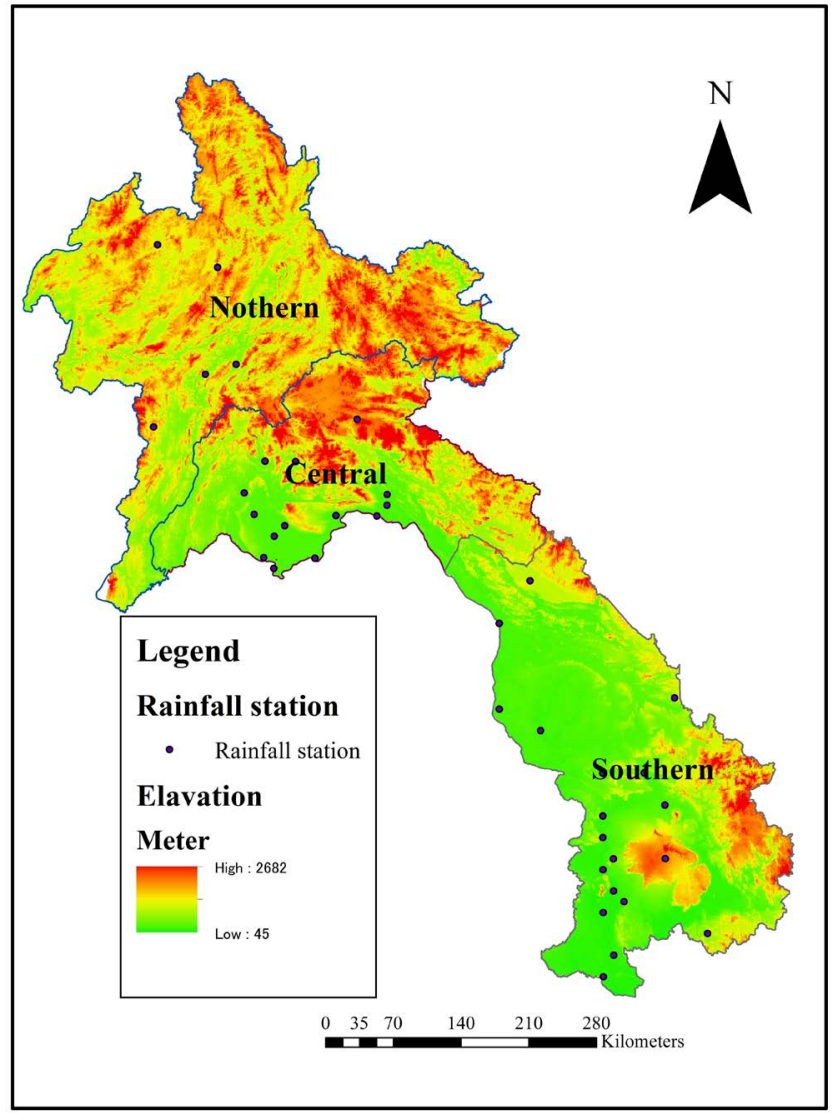

Figure 1. Study area and location of all rainfall station. 


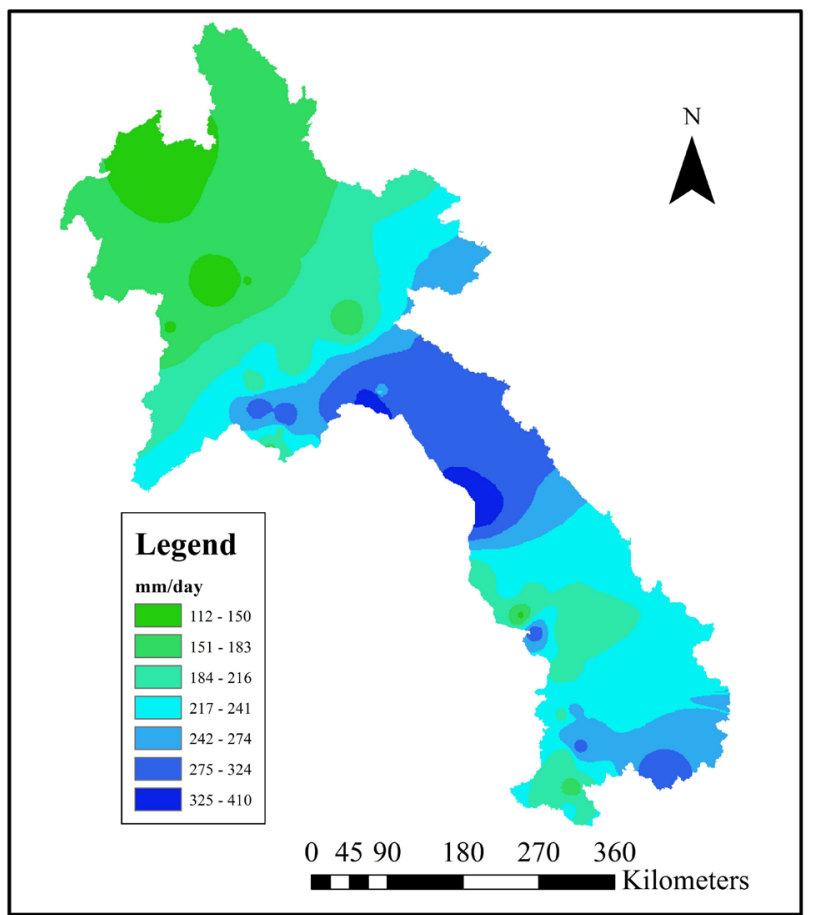

(a)

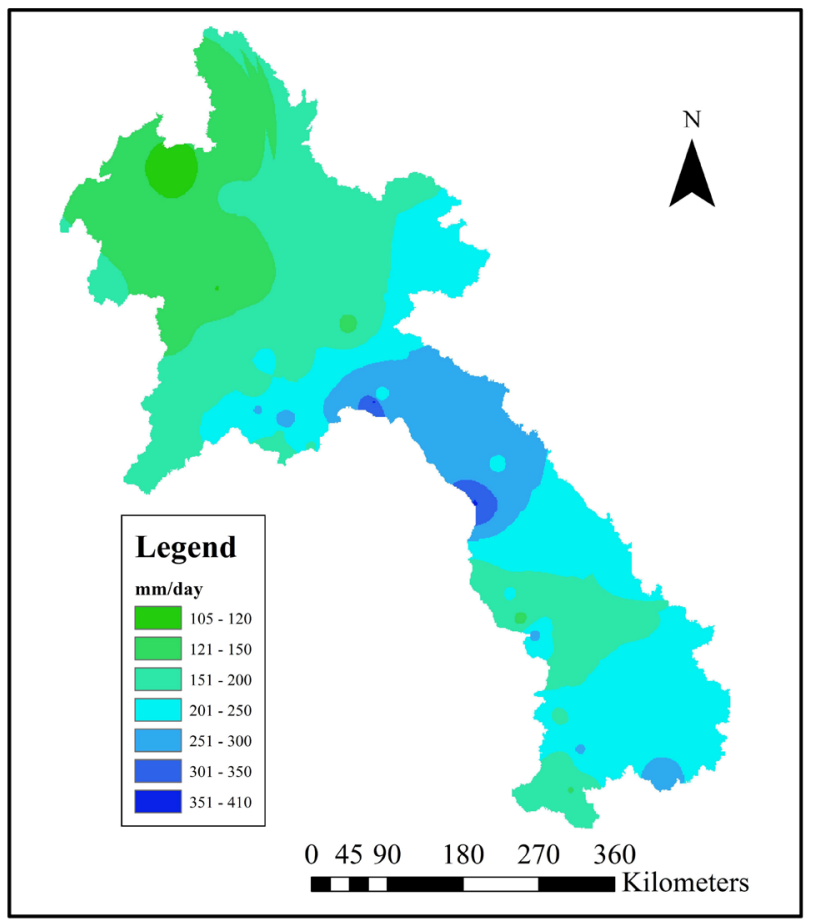

(b)

Figure 2. Return period rainfall: 50 (a) and 100 (b) years.

The digital elevation map (DEM) with a $100 \mathrm{~m}$ by $100 \mathrm{~m}$ original spatial resolution was obtained from the National University of Laos. The DEM, which is the principal source for extracting topographic factors, is one of the most important pieces of data used in various studies. 


\section{Methodology}

We have developed a model for the multi-criteria analysis of hazard maps. The AHP hazard index aims to support the identification of areas that are sensitive to flood hazards. Figure 3 shows the methodology used. The first step is the data collection stage, in which spatial data in the target area and the judgment of several experts on hazard assessment criteria are collected. Phase I includes modeling and the analysis of hazard maps such as flooding, land use changes, and climate changes. In Phase II, we calculate the weights of the hazard maps criteria. During this phase, we used AHP as a tool to measure the weights of the criteria, and the consistency ratio is computed to verify the expert judgment consistency. Finally, Phase III covers the integration of the hazard maps and the criteria weights, which generates an integrated flood hazard map. Using this integrated map, sensitive areas may be easily determined, which provides support for decision makers to design plans. The hydrological model was used to estimate 3 hazard maps, which include floods, climate changes, and land use changes.

\subsection{Floods}

The method is based on the distributed hydrological model proposed by Kazama [19] and developed by Kashiwa [20]. The hydrological processes considered in this model include precipitation, infiltration, surface runoff, base water flow and water balance in each layer. The model technically consists of a set of hydrological parameters describing the catchment properties and algorithms describing the physical processes. For each grid cell, two layers are considered in the vertical direction: the base water layer and the surface layer. The model incorporates a direct flow and base flow model used to estimate the river flow. Direct flow and base flow are calculated using kinematic wave concepts, which process meteoric water runoff using momentum and a continuity equation. Calculations of base flow use precipitation data as input and Manning's equation to determine the base flow rate, as well as infiltration from the upper layer as input data and the storage function method to determine the sub-base outflow. The infiltration rate was determinedly based on soil type. For distributed system modeling, information on river catchment geological and topographical characteristics is required to derive or measure the necessary parameters. River basin characteristics are described by a dataset (e.g., elevation, flow direction, catchment area and stream network, and land use type), which are derived from the DEM.

Manning's roughness coefficients were calibrated by trial and error; three basins, which include the northern Ou river (Figure 4(a)), the central Sane river (Figure 4(b)) and the southern Sedone river (Figure 4(c)) in Laos of 2000 were chosen as example for comparison between observed and simulated discharge. The comparison is shown in Figure 4. The performance of this model was determined using two commonly used statistical performance measures. The first is the coefficient of determination $\mathrm{R}^{2}$, and the second is the Nash-Sutcliffe efficiency E, all the stations' coefficients of 2000 are shown in Table 1 as an example. The overall results of the validation are satisfactory since all the values are 
above 0.6 , which indicates a satisfactory fit between observed and simulated hydrographs [21].

Table 1. Nash and $\mathrm{R}^{2}$ of all station in Laos from (Jan.1 to Dec.31, 2000).

\begin{tabular}{|c|c|c|c|c|c|}
\hline Station id & Nash & $\mathbf{R}^{2}$ & Station id & Nash & $\mathbf{R}^{2}$ \\
\hline 140,501 & 0.81 & 0.82 & 170,207 & 0.75 & 0.76 \\
\hline 140,504 & 0.83 & 0.87 & 170,404 & 0.73 & 0.74 \\
\hline 140,505 & 0.66 & 0.72 & 170,501 & 0.77 & 0.79 \\
\hline 140,506 & 0.74 & 0.77 & 180,203 & 0.65 & 0.66 \\
\hline 140,507 & 0.7 & 0.72 & 180,205 & 0.78 & 0.83 \\
\hline 140,705 & 0.85 & 0.89 & 180,206 & 0.87 & 0.9 \\
\hline 150,504 & 0.9 & 0.95 & 180,207 & 0.89 & 0.94 \\
\hline 150,506 & 0.84 & 0.88 & 180,213 & 0.86 & 0.88 \\
\hline 150,508 & 0.76 & 0.81 & 180,303 & 0.72 & 0.73 \\
\hline 150,602 & 0.73 & 0.74 & 180,306 & 0.85 & 0.9 \\
\hline 150,607 & 0.79 & 0.8 & 180,307 & 0.85 & 0.87 \\
\hline 160,405 & 0.81 & 0.83 & 180,308 & 0.75 & 0.77 \\
\hline 160,504 & 0.74 & 0.77 & 180,501 & 0.77 & 0.81 \\
\hline 160,505 & 0.8 & 0.81 & 190,101 & 0.69 & 0.71 \\
\hline 160,507 & 0.76 & 0.78 & 190,103 & 0.76 & 0.78 \\
\hline 160,508 & 0.74 & 0.77 & 190,205 & 0.7 & 0.72 \\
\hline 160,601 & 0.87 & 0.9 & 190,301 & 0.82 & 0.83 \\
\hline 160,602 & 0.82 & 0.86 & 190,302 & 0.84 & 0.85 \\
\hline 160,603 & 0.88 & 0.9 & 200,101 & 0.66 & 0.69 \\
\hline 170,203 & 0.78 & 0.8 & 200,204 & 0.71 & 0.76 \\
\hline
\end{tabular}

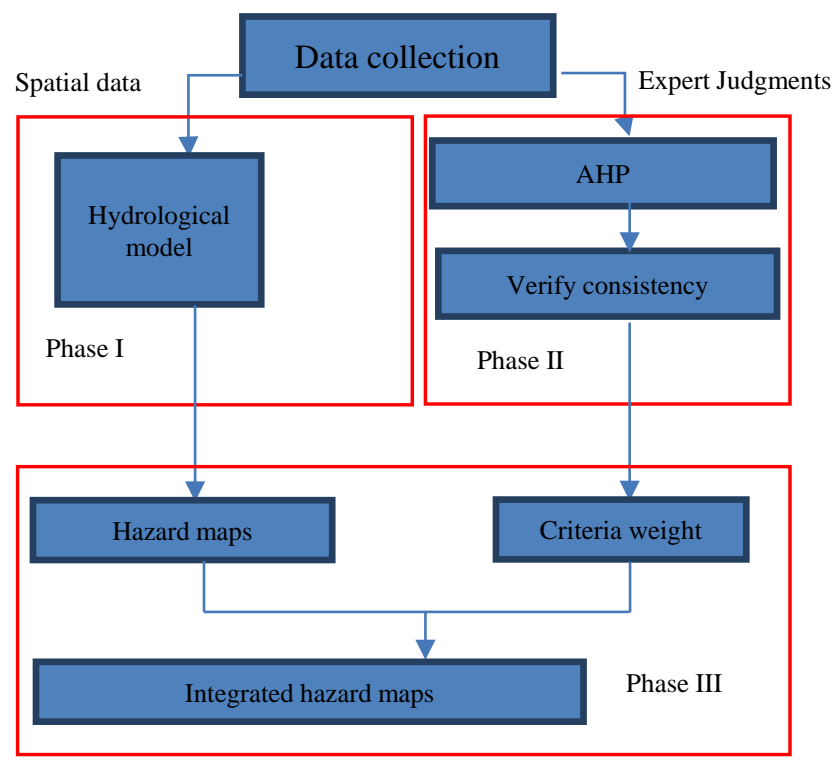

Figure 3. Methodology for integrating flood map with AHP. 


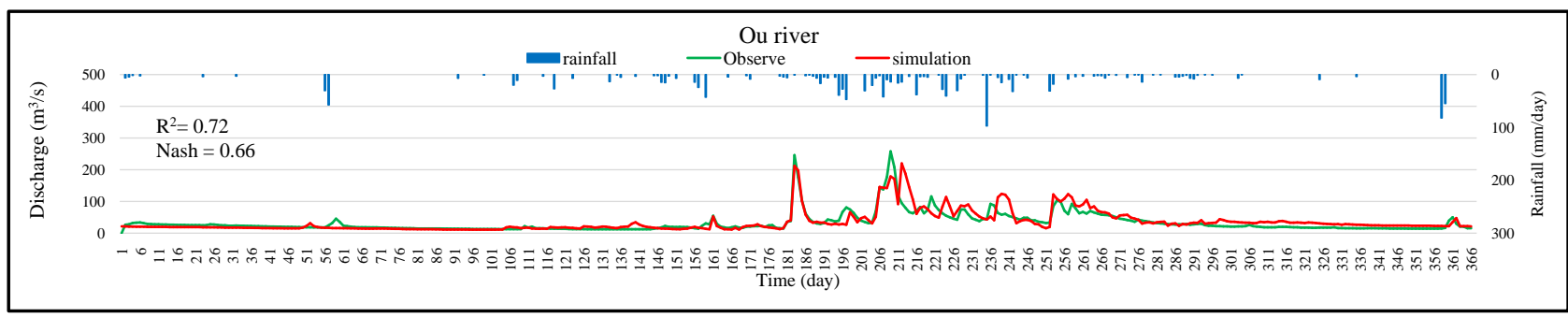

(a)

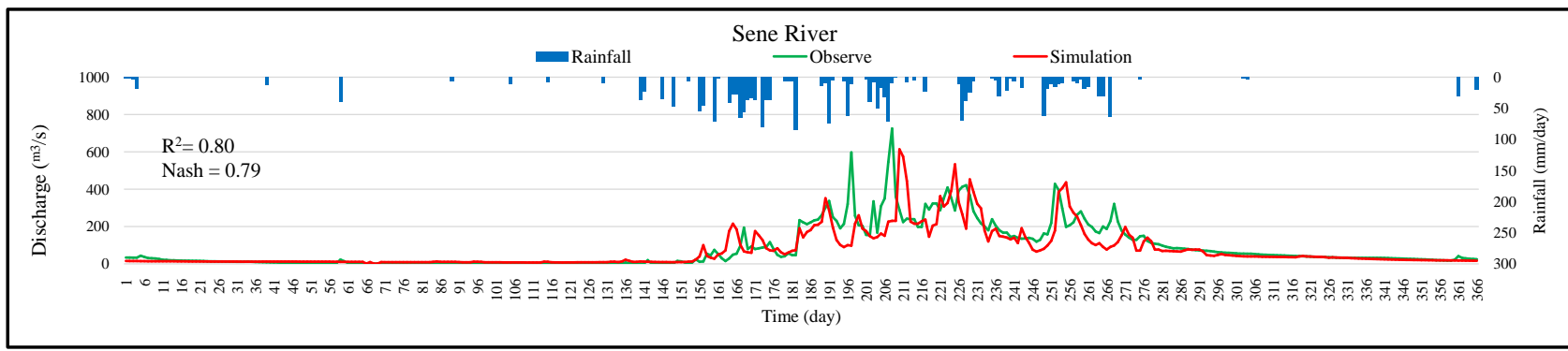

(b)

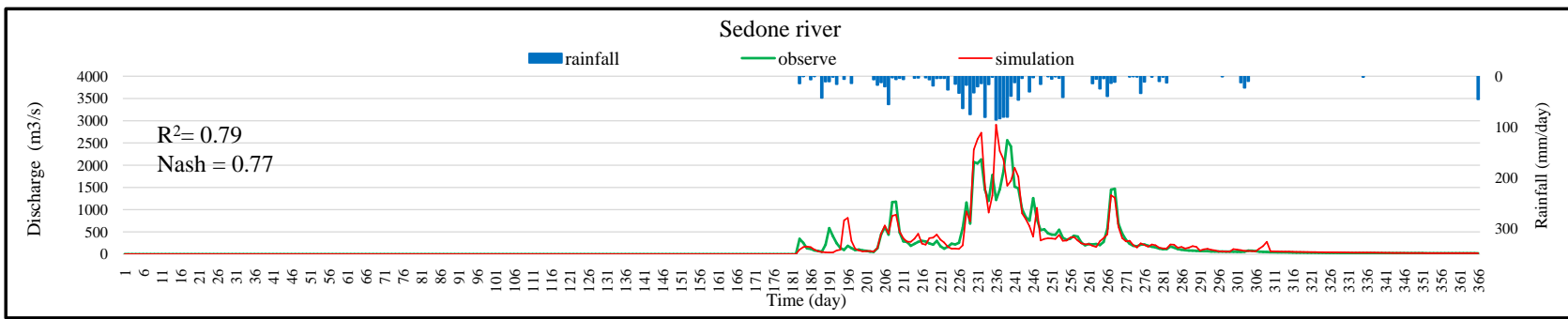

(c)

Figure 4. Comparison of observed and simulated discharges in 3 basins (Jan.1 to Dec.31, 2000).

We propose a hazard index, which is adapted from the relationship between velocity and flood depth [22], which is shown in Table 2. By considering the water depth of every grid in the flood map, we converted the map to a hazard index.

The scenario is that the water velocity from flooding areas is low, and the depth can be transformed into a hazard index. The index is scaled from zero to one, with zero describing the lowest risk and one describing the highest risk.

\subsection{Land Use Change}

Soil, topography and land cover are the most important factors that determine rainfall runoff, which leads to the scale of flood events in the catchment area. Land use changes may result in flood-drought disasters or ecological problems [23]. A land use change scenario has been generated. First, the forested area becomes an agricultural area with the assumption that the ground slope is less than $12^{\circ}$ [24]. Second, there is an expansion of urban areas based on the increased population probability, and then, a shift from rural areas to urban areas occurs. For this scenario, data from the NASA Global Grid of Probabilities of Urban Expansion were used. 
Table 2. Depth-velocity matrix showing hazards to people.

\begin{tabular}{|c|c|c|c|c|c|c|c|c|c|c|c|c|}
\hline \multirow{2}{*}{ Velocity $(\mathrm{m} / \mathrm{s})$} & \multicolumn{12}{|c|}{ Depth of flooding $(\mathrm{m})$} \\
\hline & 0 & 0.1 & 0.2 & 0.3 & 0.4 & 0.5 & 0.6 & 0.8 & 1 & 1.5 & 2 & 2.5 \\
\hline 0 & & & & & & & & & & & & \\
\hline 0.1 & & & & & & & & & & & & \\
\hline 0.25 & & & & & & & & & & & & \\
\hline 0.5 & & & & & & & & & & & & \\
\hline 1 & & & & & & & & & & & & \\
\hline 1.5 & & & & & & & & & & & & \\
\hline 2 & & & & & & & & & & & & \\
\hline 2.5 & & & & & & & & & & & & \\
\hline 3 & & & & & & & & & & & & \\
\hline 3.5 & & & & & & & & & & & & \\
\hline 4 & & & & & & & & & & & & \\
\hline 4.5 & & & & & & & & & & & & \\
\hline 5 & & & & & & & & & & & & \\
\hline & & & & & emar & & & & & & & \\
\hline & Wa & $\mathrm{rdep}$ & (m) & & & & & Haz & $\mathrm{d}$ in & & & \\
\hline & Sma & haza & $<0.2$ & & & & & & 0.2 & & & \\
\hline & Medi & $\mathrm{n}$ haz & $1<0.5$ & & & & & & -0 & & & \\
\hline & terme & iate 1 & $\operatorname{ard}<1$. & & & & & & 0.7 & & & \\
\hline & Hig & haza & $>1.5$ & & & & & & $5-$ & & & \\
\hline
\end{tabular}

\subsection{Climate Change}

Climate change is expected to increase both the magnitude and frequency of extreme precipitation events, which may lead to more intense and frequent river flooding. Several studies have shown that climate change has been a contributing factor to flooding by raising the precipitation level relative to the average annual rainfall [25] [26]. We used the inverse distance weight (IDW) spatial analysis function in ArcGIS to distribute the rainfall, which is shown in Figure 2. In this study, 50 and 100 years return period rainfall was used to represent the increase of rainfall in the future. The difference in water depth from 50 and 100 years return period hazard map can determine the sensitivity of the area regarding to the increase of rainfall. The impact of climate change on the flood hazard map was estimated by comparing 2 hazard maps for 50 and 100-year rainfall return periods because most of the historical flooding events in Laos are recorded as 50-year return periods [18]. Therefore, we chose to compare it with higher potential events in the future, which is the 100-year return period in this case. The hazard index is determined by the normalization from the differential in water depth between 50 and 100 return periods. 


\subsection{Integrated Hazards}

\subsubsection{Analytical Hierarchy Process (AHP)}

AHP is a powerful tool for multi-criteria decision-making [27]. To provide the relative weights of the criteria, it is necessary to define each criterion's relative importance, and thus, a pair-wise comparison matrix for each criterion is created to enable significance comparisons. We have 3 criteria, which include Flood, Land use change and Climate change, and thus, the matrix is 3 by 3 , and the diagonal elements are equal to 1 . The value of each row of pair-wise comparisons is determined based on expert judgments.

\subsubsection{Relative Weight of Criteria}

To obtain the criteria relative importance value, expert judgments are required. We designed and conducted a questionnaire at the Ministry of Natural Resource and Environment of Laos because most of the officers that work in this ministry have knowledge of flood hazards, climate changes, and land use impacts in Laos. Approximately 41 samples were collected from the Ministry and by using Equation (1), we obtained a value for each pair-wise comparison.

$$
R I=\frac{\left|\sum_{i=1}^{m} A_{i}-\sum_{i=1}^{m} B_{i}\right|}{m}
$$

where $R I$ is relative important of pairwise $A_{i}$ and $B_{i}$ are the responses to the questionnaire and $m$ is the number of samples.

Based on the data gathered from the questionnaire, a pair-wise comparison matrix was constructed with normalized values of each parameter from Table 3 . When we compare the inverse of the pair-wise values, the scale value is the reciprocal value. For example, the value for flooding vs. land use change is 4.90 , and thus, the value for land use change compared to flooding is $1 / 4.90=0.20$; the parameter averages for each row in the normalized matrix are computed to obtain the corresponding weight $w_{i}$ of each criterion, which is shown in Table 3.

\subsubsection{Consistency Check}

In practice, it is impossible to expect the decision maker to provide a pair-wise comparison matrix that is completely consistent. Therefore, after obtaining $w_{i}$, the consistency needs to be evaluated.

The consistency ratio is evaluated as follows:

$$
C R=\frac{C I}{R I}
$$

where $C R$ is the consistency ratio, $C I$ is the consistency index and $R I$ is a random index that is dependent on the sample size, which is shown in Table 4, where the values of $R I$ are tabulated. There are three criteria, and as a result, $R I=0.58$.

According to AHP theory, $C R$ must be less than 0.1 . $C I$ can be calculated as follows: 
Table 3. AHP pair-wise comparison matrix (A).

\begin{tabular}{|c|c|c|c|c|}
\hline Option A Option B & Flood & Land use & Climate change & Weight $\left(w_{i}\right)$ \\
\hline Flood & 1.00 & 0.50 & 0.56 & 0.21 \\
\hline Land use & 2.00 & 1.00 & 0.436 & 0.3 \\
\hline Climate change & 1.79 & 2.29 & 1.00 & 0.49 \\
\hline Sum & 4.79 & 3.79 & 2.00 & 1.00 \\
\hline
\end{tabular}

Table 4. Random index ( $R I)$ used to compute consistency ratios.

\begin{tabular}{cccccccccc}
\hline$n$ & 1 & 2 & 3 & 4 & 5 & 6 & 7 & 8 & 9 \\
\hline $\mathrm{RI}$ & 0 & 0 & 0.58 & 0.9 & 1.12 & 1.24 & 1.32 & 1.41 & 1.45 \\
\hline \multicolumn{10}{c}{$\mathrm{CI}=\frac{\lambda_{\max }-n}{n-1}$}
\end{tabular}

where $\lambda_{\max }$ is the maximum eigenvalue of the comparison matrix and $n$ is number of criteria.

$\lambda_{\max }$ is calculated according to:

$$
\begin{gathered}
\lambda_{\max }=\frac{1}{n} \times \sum_{i=1}^{n} \frac{v_{i}}{w_{i}} \\
v_{i}=A \times w_{i}
\end{gathered}
$$

where $A$ is a pair-wise comparison matrix from Table 3.

From Equation (5), we find $v_{i}$; from Equation (4), we can find $\lambda_{\max }=3.10$ and $C I=0.05$. Finally, the consistency ratio was calculated to be $C R=0.086$. Since, the $C R$ value is lower than the threshold $(0.1)$, this indicates that the expert judgments are reasonably consistent.

\subsubsection{AHP Based Hazard Index}

The AHP method was used to weight the priority of each hazard on the national scale but on the regional scale, the priority of each hazard is different. Therefore, on the regional scale, the weight of each hazard is defined by:

$$
\begin{aligned}
\mathrm{AHP}_{x y} \text { hazard index }= & \left(h_{x y, \text { flood }} \times w_{\text {flood }}\right)+\left(h_{x y, \text { land use change }} \times w_{\text {land use change }}\right) \\
& +\left(h_{x y, \text { climate chnage }} x w_{\text {climate chnage }}\right)
\end{aligned}
$$

\subsection{Hazard's Weight in Regional Scale}

$$
H W_{\text {hazard }}=\frac{a v g H W_{\text {hazard }}}{a v g H W_{f l}+a v g H W_{l u}+a v g H W_{c c}}
$$

where $H W$ is the weight of the hazards in regional scale, avgHW is the average weight of the hazards index, hazard is either $f l$, lu or $c c$ ( $f l$ is flood hazard map, $l u$ is land use hazard map and $c c$ is climate change hazard map). 


\section{Results}

\subsection{Flood Hazard Map}

A distributed hydrological model was used to simulate a flood hazard map for all of Laos. We considered the greatest water depth in every grid cell, which was determined by contributing factors during the simulation, and these included the 100-year return periods of rainfall, land types, soil hydrologic characteristics, and elevation. The results are shown in Figure 5(a), where we can see the potential flood hazard area. The results reveal that low hazard areas cover $75.88 \%$ of the total area, medium hazard areas cover $12.64 \%$, and intermediate and high hazard areas respectively cover $6.14 \%$ and $5.34 \%$. Even though the intermediate and high hazard percentages are low, we still must pay attention to land use types in those areas. The intermediate hazard areas can be divided into $89.32 \%$ forest, $10.52 \%$ agricultural and $0.15 \%$ urban. The high hazard areas can be divided into $90.51 \%$ forest, $9.23 \%$ agricultural and $0.25 \%$ urban. In addition, most of the hazard areas are distributed around the northern and southern part. The average hazard indexes in the northern, central and southern region are $0.08,0.16$, and 0.1 respectively. As seen from the results, urban areas have the smallest hazard area, and the next smallest is the agricultural areas. These areas are very important to both the country and villagers because most rural areas are dependent on agricultural products as a main source of income.

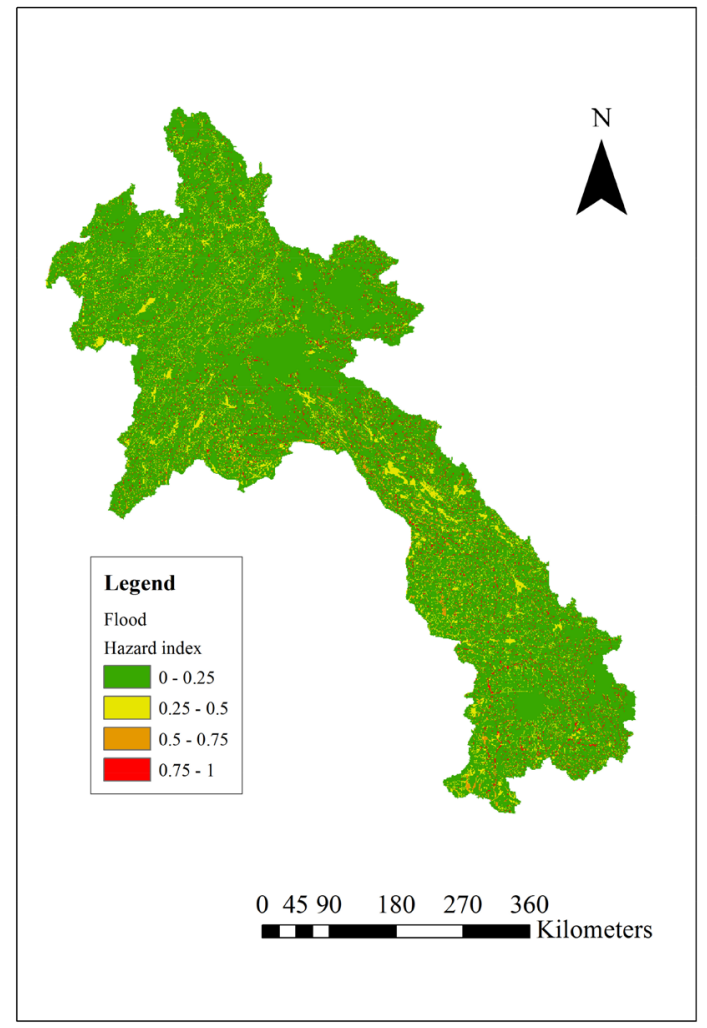

(a) 


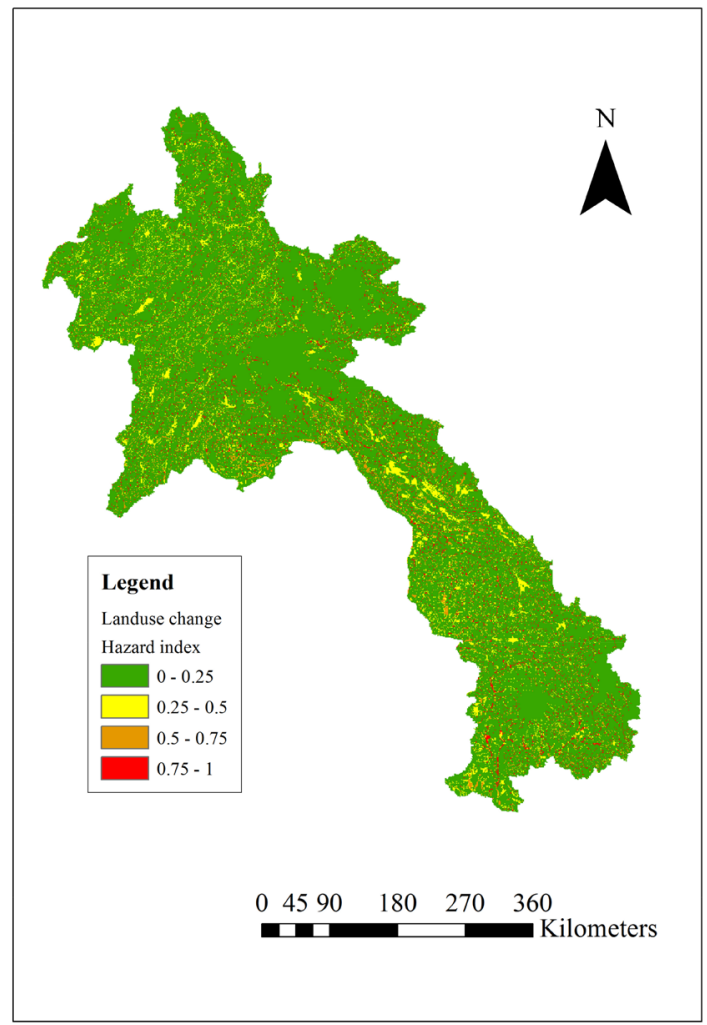

(b)

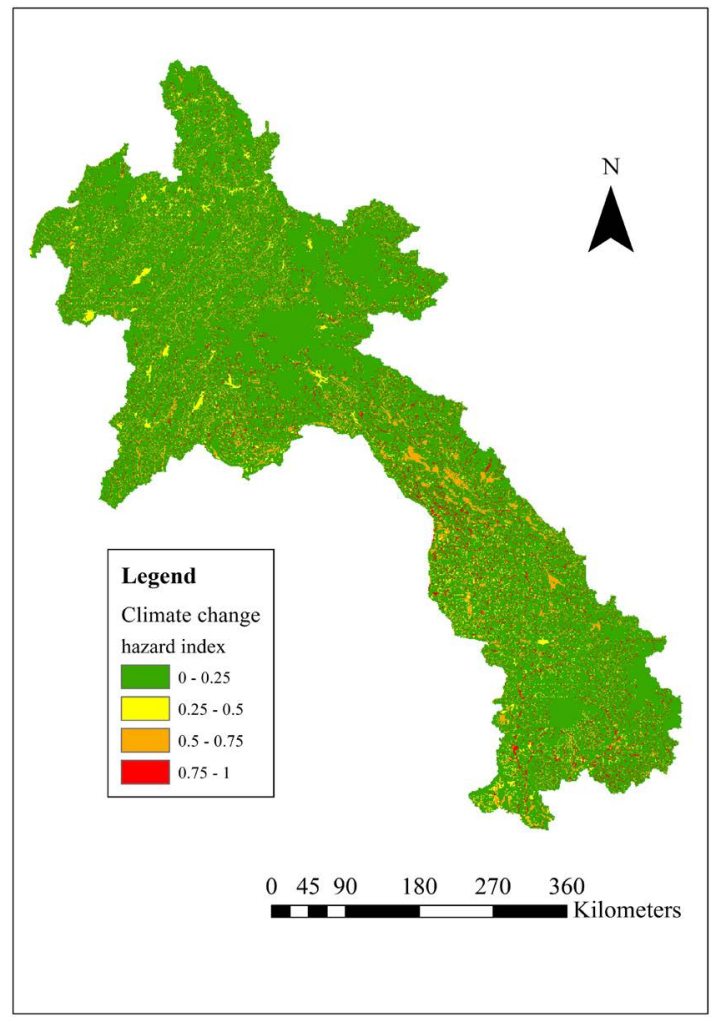

(c)

Figure 5. Hazard maps: (a) flood hazard map, (b) land use change hazard map, and (c) climate change hazard map. 


\subsection{Land Use Change Hazard Map}

The results in Figure 5(b) show the overall impact of the hazard areas, which are growing significantly; this is mostly because of the loss of forest area that slows the rainfall runoff. Without the forest area, all rainfall runoff runs directly downstream without storage or other factors to slow it down. Therefore, the hazard areas downstream are expanding. The total area where land use change occurs can be divided into $71.88 \%, 12.68 \%, 7.94 \%$ and $7.5 \%$ of low, medium, intermediate and high hazard areas, respectively. Intermediate and high hazard areas can be further divided: $89.32 \%$ of intermediate areas are in the forest, $10.55 \%$ are in agricultural areas, and $0.12 \%$ are in urban areas. We found that $90.52 \%$ of high hazard areas are in forests, $9.32 \%$ are in agricultural areas and $0.12 \%$ are in an urban area. In addition, we analyzed the increase of total hazard index between flood and land use change hazard map to identify the sensitivity of the area to land use change in 3 different regional areas namely, northern area, central area, and southern area. The average hazard indexes in the northern, central and southern region are $0.12,0.16$, and 0.13 respectively.

\subsection{Climate Change Hazard Map}

Developing countries in tropical regions are highly susceptible to floods. These regions already have high levels of precipitation, and the hydrologic cycle is significantly interlinked and sensitive to the weather. The objective here is to find areas that are sensitive to intense rainfall. Therefore, 50 and 100-year return period rainfall events were used to determine the sensitivity of these areas. From the results, it appears that low hazard areas cover $69.4 \%$ of the total area, medium hazard areas cover $12.57 \%$, and intermediate and high hazard areas respectively cover $10.18 \%$ and $7.85 \%$. As shown in Figure 5(c), for the percentage increase in water depth from 50 and 100-year return period rainfall events, many areas were susceptible to the change in rainfall intensity. Those areas show a percentage increase in water depth, which leads to an increase in flood hazards that need to be considered in a flood management plan or met with countermeasures. The average hazard indexes in the northern, central and southern region are $0.18,0.11$, and 0.21 respectively.

\subsection{Integrated Hazard Map}

The main objective of this paper is to integrate four existing hazard maps. Many studies have estimated the risk of different hazards in various zones using GIS as a tool to integrate and analyze data from different sources. The weight of each hazard is defined using the analytical hierarchy process (AHP), and a flood hazard map is created, which is shown in Figure 6. Table 5 shows both the total hazard areas and the corresponding area for each land use type. The total coverage of intermediate and high hazard areas can be separated by land covers as follows: for intermediate hazard areas, $90.44 \%$ are from forest, $9.34 \%$ are from agriculture and $0.16 \%$ are from urban areas; for high hazard areas, $88.11 \%$ are from forest, $9.79 \%$ are from agriculture and $2.1 \%$ are from urban areas. 


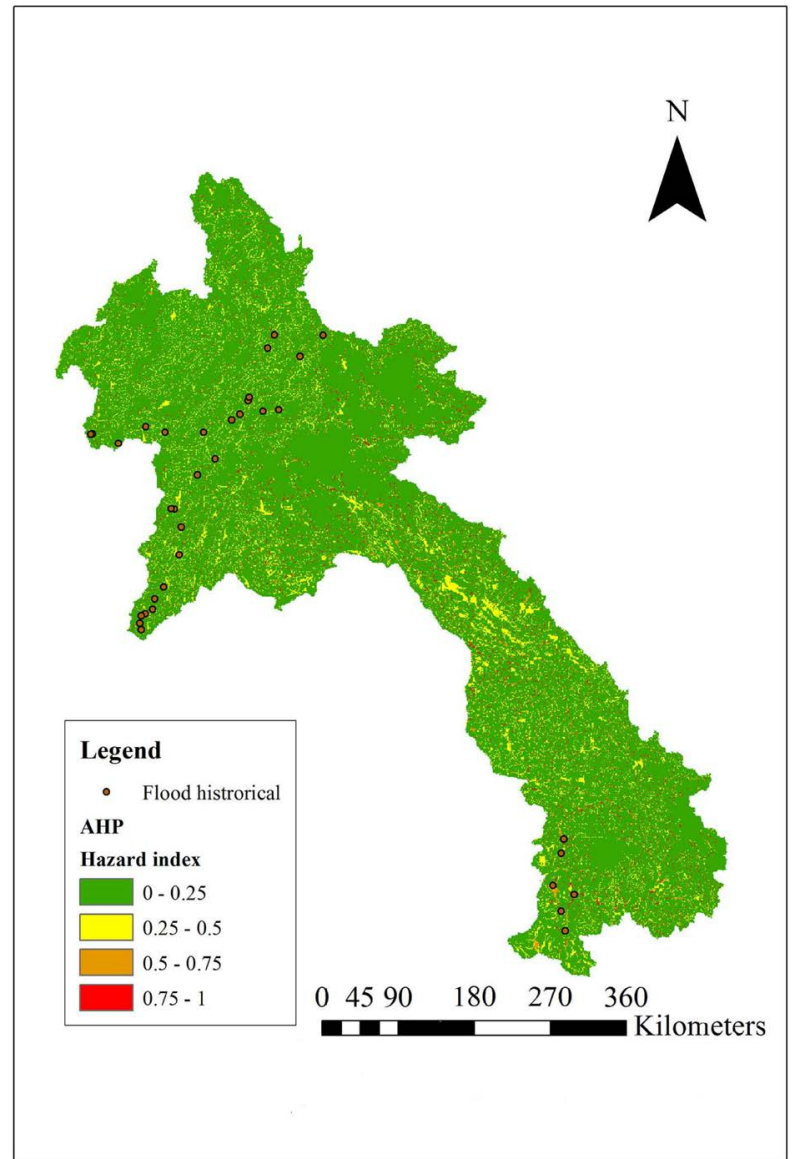

Figure 6. AHP hazard map and historical events.

Table 5. Hazard area and corresponding percentages.

\begin{tabular}{ccc}
\hline & Area $\left(\mathrm{km}^{2}\right)$ & Percentage (\%) \\
\hline Hazard index for Laos & 188,053 & 87.44 \\
Low hazard 0 - 0.25 & 17,469 & 8.12 \\
Medium hazard $0.25-0.5$ & 5220 & 2.42 \\
Intermediate hazard $0.5-0.75$ & 4309 & 2.00 \\
High hazard $0.75-1$ & & 87.58 \\
Hazard index of agricultural area & 16,144 & 8.35 \\
Low hazard 0 - 0.25 & 1540 & 2.35 \\
Medium hazard $0.25-0.5$ & 434 & 1.70 \\
Intermediate hazard $0.5-0.75$ & 315 & \\
High hazard $0.75-1$ & & 81.40 \\
Hazard index of urban area & 267 & 10.97 \\
Low hazard 0 - 0.25 & 36 & 3.96 \\
Medium hazard 0.25 - 0.5 & 13 & 3.66 \\
Intermediate hazard $0.5-0.75$ & 12 & \\
High hazard $0.75-1$ & &
\end{tabular}


Continued

\begin{tabular}{ccc}
\hline Hazard index of forest area & & \\
Low hazard $0-0.25$ & 160,121 & 88.50 \\
Medium hazard $0.25-0.5$ & 13,617 & 7.52 \\
Intermediate hazard $0.5-0.75$ & 3969 & 2.19 \\
High hazard $0.75-1$ & 3201 & 1.76 \\
\hline
\end{tabular}

\subsection{Land Use Change Hazard Map}

The results in Figure 5(b) show the overall impact of the hazard areas, which are growing significantly; this is mostly because of the loss of forest area that slows the rainfall runoff. Without the forest area, all rainfall runoff runs directly downstream without storage or other factors to slow it down. Therefore, the hazard areas downstream are expanding. The total area where land use change occurs can be divided into $71.88 \%, 12.68 \%, 7.94 \%$ and $7.5 \%$ of low, medium, intermediate and high hazard areas, respectively. Intermediate and high hazard areas can be further divided: $89.32 \%$ of intermediate areas are in the forest, $10.55 \%$ are in agricultural areas, and $0.12 \%$ are in urban areas. We found that $90.52 \%$ of high hazard areas are in forests, $9.32 \%$ are in agricultural areas and $0.12 \%$ are in an urban area. In addition, we analyzed the increase of total hazard index between flood and land use change hazard map to identify the sensitivity of the area to land use change in 3 different regional areas namely, northern area, central area, and southern area. The average hazard indexes in the northern, central and southern region are $0.12,0.16$, and 0.13 respectively.

\section{Discussion}

According to Table 5, the high hazard areas have shallow water depth, and most of them include forest areas. Similarly, forest areas comprise the largest percentage of the area, which is followed by agricultural and urban areas. Comparing the hazard areas before integration (flood, land use change and climate change) and after integration (integrated hazard map by AHP), we found that most of the high hazard areas (90.73\%) were located in forest areas, which increased compared to the hazard maps before integration (flood (90.47\%), land use change $(90.54 \%)$ and climate change $(89.80 \%) ; 8.93 \%$ of the integrated hazard map was located in urban areas, which increased from the climate change hazard map (8.16\%) but decreases when compared to the flood hazard map (9.38\%) and land use change hazard map (9.21\%); and $0.34 \%$ of the integrated hazard map was located in agricultural areas, which increased from the flood $(0.15 \%)$ and land use change hazard map (0.25\%) but decreased from the climate hazard map (2.04\%). Although, each region has its own sensitivity to hazard, the priority of each hazard from the AHP method can reflect the overall situation of hazard in national scale. Based on these results, it is important to focus priorities on flood protection and management plans in high hazard areas that are in urban areas to minimize the consequences of flood damage. 
To validate the hazard weights of AHP method, we compared them with the hazard weight from the average hazard index in Equation (7) for intermediate and high hazard indices. The weights from the AHP method were acquired from experts' judgments. The experts' judgments rely on their involvement in hazard events that occurred in accessible areas such as urban, agricultural and paddy field areas; the experts did not take into consideration the hazard events that occurred in areas that are hard to access such as mountainous and forest areas. The areas were divided into 3 regions (southern, central and northern) to monitor the hazard events because the same hazard can have different magnitudes depending on the region. Therefore, we used Equation (7) to estimate the hazard weight for intermediate and high hazard indices and excluded the mountainous areas of the flood, land use change, and climate change hazard map in each region. From the results, the composition of the hazard weight from the average hazard index in the northern and southern regions (Figure 7(a) and Figure 7(b)) have similar proportions with the hazard weight from AHP method (Figure $7(\mathrm{c})$ ). The hazard weight of climate change in the northern region (0.47) is slightly smaller than that from AHP method (0.49), the hazard weight of land use change (0.23) is larger than the AHP method (0.21), and for flood hazard both weights from averaged indices and AHP method have similar results (0.3). For the southern area, the weights of flood, climate change land use change hazard map are $0.23,0.29$ and 0.48 , respectively, which are quite similar to the hazards weight of AHP method. For the central area (Figure $7(\mathrm{~d})$ ), the proportion of the hazards weight is significantly different from the weight of AHP method; the weight from the land use change is 0.39 , climate change is 0.33 and flood is 0.28. By comparing the weights from AHP method and the weights from the average hazard index, we can conclude that the northern and southern regions have similar hazard weights, while the central region is susceptible to land use change more than another region. The northern and southern regions are susceptible to climate change more than land use change, and the central region is susceptible to land use change. Laos national report [18] 2 states that the magnitude of hazard increases in the northern and southern region because of the

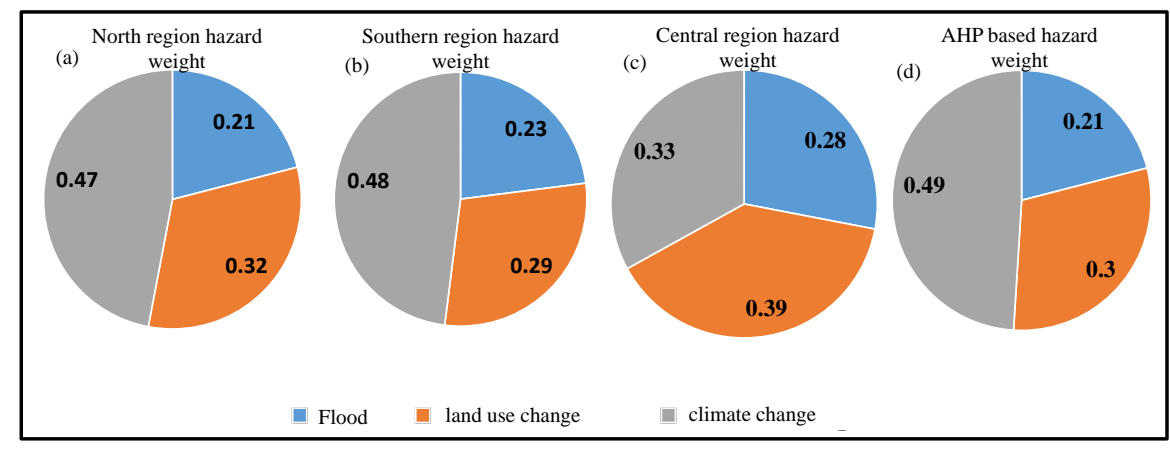

Figure 7. Comparison of hazard weight from 3 regional area and hazard weight from AHP method: (a) northern region (b) Southern region (c) central region and (d) AHP based hazard weight. 
climate change, which is the same trend with our results. In addition, the AHP method compiles various hazards to create an integrated hazard map by determining their weight. Furthermore, the AHP method has proved its consistency in the climate change susceptibility to the hazard map in the northern and southern region. The hazard maps were able to show similar susceptibility of different hazards to the real events, thus indicating the reliability of the AHP method to be applied in Laos, particularly in those areas where climate change susceptibility is extremely vulnerable.

30 flood events determined by the United Nations Office for Disaster Risk Reduction are used for comparison for the validation of a hazard map. Historical flood events are shown as red circles in Figure 6. Only events with a high depth of water in the named villages were considered. These locations are used for validating the flood hazard map. In Figure 6, 4 events (13\%) are in small hazard areas $(0-0.25), 9$ events $(30 \%)$ are in the medium hazard areas $(0.25-0.5), 7$ events $(23 \%)$ are in intermediate hazard areas $(0.5-0.75)$, and 10 events (34\%) are in high hazard areas $(0.75-1.0)$, which is shown in Table 6. From these results, the relatively high consistency of the flood hazard map can be seen, because most of the flood events based on the historical data are in intermediate to high hazard areas. Hence, the reliability of the integrated hazard map is confirmed.

The integrated hazard map can be used in combination with other maps, such as the future development plan from the government or private sector, and thus, areas of risk in the development of agricultural areas or expansion of urban areas can be verified. By comparing two land use datasets (current land use and the future land use change scenario) with the integrated hazard map, the impact from the expansion of agricultural and urban areas can be predicted. For example, before the change in land use, the agricultural areas located in intermediate and high hazard areas were $432 \mathrm{~km}^{2}$ and $315 \mathrm{~km}^{2}$, respectively, and after land use change, the agricultural areas located in intermediate and high hazard areas were $4250 \mathrm{~km}^{2}$ and $3375 \mathrm{~km}^{2}$, respectively (Figure 8(a)). Additionally, before the changes in land use, urban areas located in intermediate and high hazard areas were $13 \mathrm{~km}^{2}$ and $12 \mathrm{~km}^{2}$, respectively, and after land use changes, these areas increased to $32 \mathrm{~km}^{2}$ and $34 \mathrm{~km}^{2}$, respectively (Figure $8(\mathrm{~b})$ ). The results show that in terms of the impact area, the agricultural areas have a more significant impact than urban areas if the trend in changing land use is according to our assumptions. To minimize the impact from the expansion of agricultural and urban areas, those areas located in hazard areas must be avoided.

Flooding can be alleviated using agricultural land to store water. For example, an agricultural area can act as a sub-catchment to reduce the impact of flooding on urban and rural areas. In addition, it is necessary to include strategies for flood mitigation downstream from urban areas. With planning, areas prone to flooding will be able to store floodwaters in rural areas. Moreover, water from flooded areas can be used for irrigation systems to develop a tolerance to climate 
change. The advantage of the proposed integrated hazard map is its ability to provide an overall assessment of flood hazard areas at the national scale. The application can also be extended to assess hazard zones in urban areas.

Table 6. Flood event locations with hazard index.

\begin{tabular}{|c|c|c|c|c|}
\hline Hazard index & Lon & Lat & Hazard index & Name of village \\
\hline 0.13 & 100.5 & 19.67 & Small hazard & Southwestern Houamuang \\
\hline 0.21 & 100.81 & 19.58 & Small hazard & Southeastern Pavan \\
\hline 0.22 & 101.71 & 19.26 & Small hazard & Eastern Simoung \\
\hline 0.23 & 102.48 & 20.63 & Small hazard & Western Donkha \\
\hline 0.25 & 101.34 & 19.71 & Medium hazard & Western Donxai \\
\hline 0.32 & 101.26 & 17.93 & Medium hazard & Southwestern Pongdet \\
\hline 0.37 & 102.28 & 20.1 & Medium hazard & Southeastern Houaykho \\
\hline 0.43 & 101.91 & 19.44 & Medium hazard & Eastern Keomani \\
\hline 0.44 & 102.09 & 19.86 & Medium hazard & Western Pongvan \\
\hline 0.47 & 101.12 & 17.6 & Medium hazard & Northern Nanoy \\
\hline 0.48 & 101.12 & 17.75 & Medium hazard & Southern Pakxong \\
\hline 0.48 & 101.46 & 18.89 & Medium hazard & Eastern Koum \\
\hline 0.49 & 102.62 & 19.97 & Medium hazard & Northern Sopchia \\
\hline 0.54 & 101.16 & 17.77 & Intermediate hazard & Northern Nahouaxang \\
\hline 0.55 & 102.44 & 19.96 & Intermediate hazard & Northwestern Thapho \\
\hline 0.56 & 105.79 & 15.24 & Intermediate hazard & Southwestern Dua-Nua \\
\hline 0.57 & 101.42 & 18.9 & Intermediate hazard & Western Pakxong \\
\hline 0.58 & 105.83 & 14.41 & Intermediate hazard & Southwestern Nangloybanna \\
\hline 0.67 & 103.11 & 20.78 & Intermediate hazard & Northern Don \\
\hline 0.71 & 105.82 & 15.39 & Intermediate hazard & Southern Kham-yet \\
\hline 0.76 & 105.7 & 14.9 & High hazard & Eastern Vangpham \\
\hline 0.76 & 105.93 & 14.8 & High hazard & Southern Pakkeng \\
\hline 0.76 & 101.77 & 19.72 & High hazard & Southern Mouang \\
\hline 0.76 & 102.56 & 20.78 & High hazard & Southern Pakken \\
\hline 0.76 & 101.24 & 17.82 & High hazard & Eastern Poungchounglu \\
\hline 0.76 & 100.52 & 19.68 & High hazard & Northwestern Namhang \\
\hline 0.76 & 101.36 & 18.06 & High hazard & Southern Pathoumphon \\
\hline 0.76 & 101.54 & 18.7 & High hazard & Southwestern Nonsa-At \\
\hline 0.78 & 101.1 & 17.67 & High hazard & Northern Bosan \\
\hline 0.79 & 105.79 & 14.62 & High hazard & Western Thapchan \\
\hline
\end{tabular}




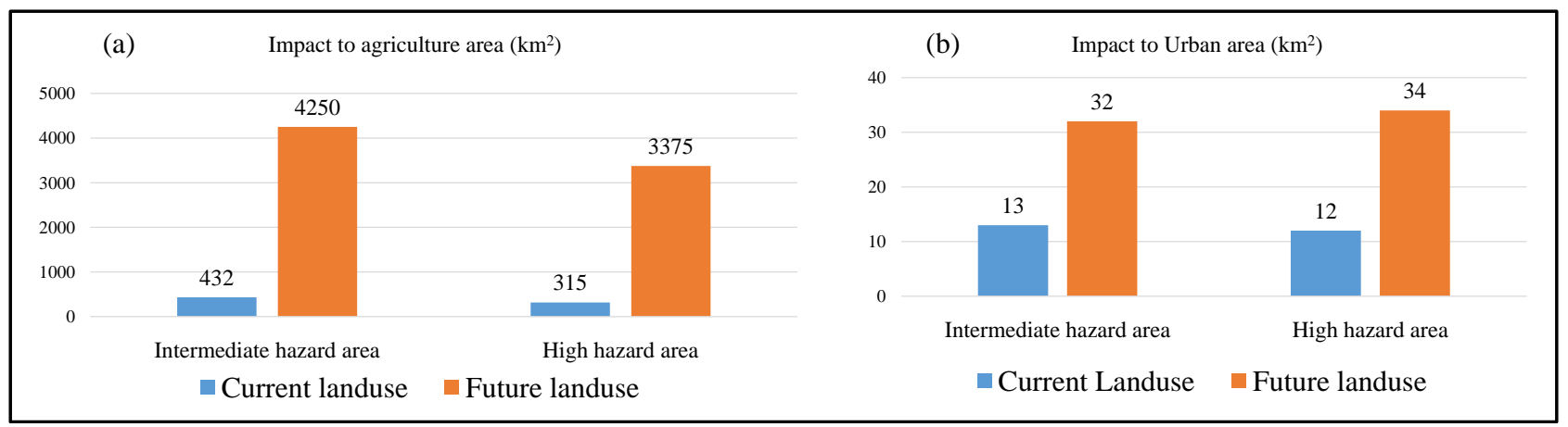

Figure 8. Impact area of current land use and future land use: (a) agriculture area and (b) urban area.

\section{Conclusions}

The main purpose of this study is to develop an integrated hazard map that is reliable on a national scale. The result is an integrated map of flooding, land use change and climate change hazards developed using AHP to perform the integration. The flood hazard map was generated using a hydrological model, which was scaled with a hazard index. The results show that urban areas have few high hazard flooding indexes when compared with other land use types. The land use change hazard map was generated based on the scenario that all forested areas with less than 12 degree slopes are deforested for agricultural use. The high hazard areas increase from approximately $5.34 \%$ in the flood hazard map to $7.5 \%$ of the total area. This indicates that forest density is a significant factor in preventing flooding in our study area. The climate change hazard map was generated by examining the differences in rainfall between the 50 and 100-year return period maps to show the areas susceptible to changes in rainfall intensity. The results show the hazard magnitude increased in northern and southern regions. Additionally, weights from the AHP meted provide a capability to show the susceptibility to hazards in each area similar to that of the Laos national report. Therefore, the AHP method is reliable and can be adopted for integrated hazard maps.

This study provides an important and reliable methodology for the development of integrated hazard maps using multi-criteria decision analysis, such as AHP. Furthermore, exposure data on population and economic losses in a hazard area can provide more detail and improve the results.

\section{Acknowledgements}

This research was partially supported by the Grants-in-Aid for Scientific Research (B), 2015-2017 (15H05218, So Kazama) from the Ministry of Education, Science, Sports and Culture. The authors are grateful to the Environmental Research and Technology Development Fund (s-14) from the Ministry of the Environment, Japan. Special thanks are extended to Dr. Sengrasong Phrakonhkam for support and assistance conducting questionnaires for the AHP analysis. 


\section{Conflicts of Interest}

The authors declare no conflicts of interest regarding the publication of this paper.

\section{References}

[1] Bakker, E.J. (1990) Demand for Rainfall Insurance in the Semi-Arid Tropics of India.

[2] Jongman, B., Kreibich, H., Apel, H., Barredo, J.I., Bates, P.D., Feyen, L., et al. (2012) Comparative Flood Damage Model Assessment: Towards a European Approach. Natural Hazards and Earth System Sciences, 12, 3733-3752. https://doi.org/10.5194/nhess-12-3733-2012

[3] Golian, S., Saghafian, B. and Maknoon, R. (2010) Derivation of Probabilistic Thresholds of Spatially Distributed Rainfall for Flood Forecasting. Water Resources Management, 24, 3547-3559. https://doi.org/10.1007/s11269-010-9619-7

[4] Winsemius, H.C., Aerts, J.C.J.H., van Beek, L.P.H., Bierkens, M.F.P., Bouwman, A., Jongman, B., et al. (2016) Global Drivers of Future River Flood Risk. Nature Climate Change, 6, 381-385. https://doi.org/10.1038/nclimate2893

[5] Dewan, A.M., Islam, M.M., Kumamoto, T. and Nishigaki, M. (2007) Evaluating Flood Hazard for Land-Use Planning in Greater Dhaka of Bangladesh Using Remote Sensing and GIS Techniques. Water Resources Management, 21, 1601-1612. https://doi.org/10.1007/s11269-006-9116-1

[6] Tehrany, M.S., Pradhan, B. and Jebur, M.N. (2013) Spatial Prediction of Flood Susceptible Areas Using Rule Based Decision Tree (DT) and a Novel Ensemble Bivariate and Multivariate Statistical Models in GIS. Journal of Hydrology, 504, 69-79. https://doi.org/10.1016/j.jhydrol.2013.09.034

[7] Metz, B., Davidson, O.R., Bosch, P.R., Dave, R. and Meyer, L.A., Eds. (2007) Contribution of Working Group III to the Fourth Assessment Report of the Intergovernmental Panel on Climate Change. Cambridge University Press, Cambridge, UK and New York, USA.

[8] Westra, S., Fowler, H.J., Evans, J.P., Alexander, L.V., Berg, P., Johnson, F., et al. (2014) Future Changes to the Intensity and Frequency of Short-Duration Extreme Rainfall. Reviews of Geophysics, 52, 522-555. https://doi.org/10.1002/2014RG000464

[9] Marzocchi, W., Garcia-Aristizabal, A., Gasparini, P., Mastellone, M.L. and Ruocco, A.D. (2012) Basic Principles of Multi-Risk Assessment: a Case Study in Italy. Natural Hazards, 62, 551-573. https://doi.org/10.1007/s11069-012-0092-x

[10] Douglas, J. (2007) Physical Vulnerability Modelling in Natural Hazard Risk Assessment. Natural Hazards and Earth System Sciences, 7, 283-288. https://doi.org/10.5194/nhess-7-283-2007

[11] Bovolo, C.I., Abele, S.J., Bathurst, J.C., Caballero, D., Ciglan, M., Eftichidis, G. and Simo, B. (2009) A Distributed Framework for Multi-Risk Assessment of Natural Hazards Used to Model the Effects of Forest Fire on Hydrology and Sediment Yield. Computers \& Geosciences, 35, 924-945. https://doi.org/10.1016/j.cageo.2007.10.010

[12] Fernández, D.S. and Lutz, M.A. (2010) Urban Flood Hazard Zoning in Tucumán Province, Argentina, Using GIS and Multicriteria Decision Analysis. Engineering Geology, 111, 90-98. https://doi.org/10.1016/j.enggeo.2009.12.006

[13] Kazakis, N., Kougias, I. and Patsialis, T. (2015) Assessment of Flood Hazard Areas at a Regional Scale Using an Index-Based Approach and Analytical Hierarchy 
Process: Application in Rhodope-Evros Region, Greece. Science of the Total Environment, 538, 555-563. https://doi.org/10.1016/j.scitotenv.2015.08.055

[14] Stefanidis, S. and Stathis, D. (2013) Assessment of Flood Hazard Based on Natural and Anthropogenic Factors Using Analytic Hierarchy Process (AHP). Natural Hazards, 68, 569-585. https://doi.org/10.1007/s11069-013-0639-5

[15] Gigović, L., Pamučar, D., Bajić, Z. and Drobnjak, S. (2017) Application of GIS-Interval Rough AHP Methodology for Flood Hazard Mapping in Urban Areas. Water, 9, Article ID: 360. https://doi.org/10.3390/w9060360

[16] Todd, C.E.D., Goss, A.M., Tripathy, D. and Harbor, J.M. (2007) The Effects of Landscape Transformation in a Changing Climate on Local Water Resources. Physical Geography, 28, 21-36. https://doi.org/10.2747/0272-3646.28.1.21

[17] Pumo, D., Arnone, E., Francipane, A., Caracciolo, D. and Noto, L.V. (2017) Potential Implications of Climate Change and Urbanization on Watershed Hydrology. Journal of Hydrology, 554, 80-99. https://doi.org/10.1016/j.jhydrol.2017.09.002

[18] (2012) ADPC: Lao PDR National Assessment Report on Disaster Risk Reduction. Laos National Report.

[19] Kazama, S., Hyejin, K. and Sawamoto, M. (2004) Uncertainty of Morphological Data for Rainfall-Runoff Simulation. Proceedings of the International Conference on Sustainable Water Resources Management in the Changing Environment of the Monsoon Region, Colombo Sri Lanka, 17-19 November 2004, 400-406.

[20] Kashiwa, S., Asaoka, Y. and Akira, K. (2010) Flood Analysis Modeling of Snow Melting and Estimation. Proceeding of the rivers technology, 1-4 December 2010, 289-294.

[21] Moriasi, D.N., Arnold, J.G., van Liew, M.W., Bingner, R.L., Harmel, R.D. and Veith, T.L. (2007) Model Evaluation Guidelines for Systematic Quantification of Accuracy in Watershed Simulations. American Society of Agricultural and Biological Engineers, 50, 885-900. https://doi.org/10.13031/2013.23153

[22] Priest, S.J., Tapsell, S., Penning-Rowsell, E. and Viavattene, C. (2008) Building Models to Estimate Loss of Life for Flood Events.

[23] Gebremicael, T.G., Mohamed, Y.A., Betrie, G.D., van der Zaag, P. and Teferi, E. (2013) Trend Analysis of Runoff and Sediment Fluxes in the Upper Blue Nile basin: A Combined Analysis of Statistical Tests, Physically-Based Models and Landuse Maps. Journal of Hydrology, 482, 57-68. https://doi.org/10.1016/j.jhydrol.2012.12.023

[24] van Chuong, H. (2008) Multicriteria Land Suitability Evaluation for Crops Using GIS at Community Level in Central Vietnam with Case Study in Thuy Bang-Thua Thien Hue province. International Symposium on Geoinformatics for Spatial Infrastructure Development in Earth and Allied Sciences 2008, Hanoi, Vietnam, 9-11 December 2008.

[25] Li, Y.-F., Guo, Y. and Yu, G. (2013) An Analysis of Extreme Flood Events during the Past 400 Years at Taihu Lake, China. Journal of Hydrology, 500, 217-225. https://doi.org/10.1016/j.jhydrol.2013.02.028

[26] Hirabayashi, Y., Kanae, S., Emori, S., Oki, T. and Kimoto, M. (2008) Global Projections of Changing Risks of Floods and Droughts in a Changing Climate. Hydrological Sciences Journal, 53, 754-772. https://doi.org/10.1623/hysj.53.4.754

[27] Saaty, T.L. (1994) How to Make a Decision: The Analytic Hierarchy Process. INFORMS Journal on Applied Analytics, 24, 19-43.

https://doi.org/10.1287/inte.24.6.19 